\title{
Comparison Between Ultrathin Films of YSZ Deposited at the Solid Oxide Fuel Cell Cathode/Electrolyte Interface by Atomic Layer Deposition, Dip- Coating or Sputtering
}

\author{
M. Benamira ${ }^{1}$, A. Ringuedé ${ }^{1}$, M. Cassir ${ }^{*}, 1$, D. Horwat ${ }^{2}$, J.F. Pierson ${ }^{2}$, P. Lenormand $^{3}$, F. Ansart ${ }^{3}$, \\ J.M. Bassat ${ }^{4}$ and J. Fullenwarth ${ }^{4}$ \\ ${ }^{I}$ Laboratoire d'Electrochimie, Chimie des Interfaces et Modélisation pour l'Energie (LECIME), UMR 7575 CNRS, \\ Chimie Paris Tech, France \\ ${ }^{2}$ Institut Jean Lamour, Département CP2S, Ecole des Mines, CS14234 Parc de Saurupt, F-54042 Nancy Cedex, France \\ ${ }^{3}$ CIRIMAT/LCMIE/UMR5085, Université Paul Sabatier, bât IIR1, 118, route de Narbonne 31062, Toulouse Cedex 04, \\ France \\ ${ }^{4}$ ICMCB-CNRS, Université Bordeaux I, 87 Av. Schweitzer, 33608 Pessac Cedex, France
}

\begin{abstract}
The effect of an $80 \mathrm{~nm}$ YSZ interfacial layer, deposited onto a YSZ pellet by different techniques (dip-coating, sputtering and atomic layer deposition) at the SOFC cathode/electrolyte interface to allow a maximum adhesion of the thick cathode layer, was thoroughly analysed. The LSM cathode was deposited on the solid electrolyte by painting and sintered in air at $1200^{\circ} \mathrm{C}$ for $2 \mathrm{~h}$. The morphological and structural analyses of the samples were performed by scanning electron microscopy and X-ray diffraction; their electrical properties were examined between 390 and $700^{\circ} \mathrm{C}$ by electrochemical impedance spectroscopy. The impedance responses showed three different contributions. The highfrequency arc is attributed to the YSZ electrolyte. The electrode processes associated with the medium- and lowfrequency arcs were discussed. The electrochemical performance was influenced by the microstructure at the electrode/electrolyte interface.
\end{abstract}

Keywords: SOFC, thin layers, impedance spectroscopy, electrical properties, lanthanum strontium manganite (LSM), yttriadoped zirconia (YSZ).

\section{INTRODUCTION}

SOFCs devices present several advantages with respect to low temperature fuel cells, mainly in the field of cogeneration and in the transport area as auxiliary power units. The development of these solid electrolyte systems is supported by intense research and demonstration activities in most of the important industrial countries. The planar configuration still suffers from many technical problems, but appears as the most attractive one for the future, with some remarkable advances on innovative fabrication techniques and a wide variety of electrode and electrolyte materials. Although the feasibility of SOFCs has been clearly demonstrated, the usual working temperature, around $800^{\circ} \mathrm{C}$, involves the use of expensive ceramic interconnects and to a premature ageing of the components. Therefore, it appears crucial to decrease their operation temperature in order to reach, as a first step, some niche markets.

However, the increase in the lifetime at $600-700^{\circ} \mathrm{C}$ leads to an insufficient ionic conductivity of the electrolyte and to an increase in the electrode overpotentials. At these temperatures, it is essential to lower the electrolyte resistance

*Address correspondence to this author at the Laboratoire d'Electrochimie et de Chimie Analytique (LECA), UMR 7575 CNRS, Chimie ParisTech, Paris 6, France; Tel: +33-1-55426387; Fax: +33-1-44276750;

E-mail: michel-cassir@enscp.fr either by reducing the thickness of the usual electrolyte, i.e. yttria-stabilised zirconia, YSZ, or by finding new materials with a significantly higher conductivity. In any case, the use of thin layers cannot be ignored nowadays. Furthermore, in order to increase the electrochemical performance of the electrode materials and, in particular, on the cathode side (where the oxygen reduction overpotential is known to be high), the use of ultrathin interface layers over which would be deposited thick layers of the same material would reduce significantly the associated overpotentials.

Some of the present authors were among the first to privilege ultra thin electrolytes for SOFC application [1-6]. This key issue offers several opportunities; not only in order to lower the working temperature and use stainless steels interconnects, but also to avoid high temperature annealing treatments. Another fundamental aspect is to control the electrical conductivity and electrochemical reactions by optimising the thin-layered nanocrystalline structure. It is now admitted that nanomaterials present very often an unusual conductivity and thermal stability due to the high ratio of intergranular area with respect to the total grain area [7-12]. One should keep in mind that, in principle, the effective intergranular resisistivity is a decreasing function of the grain size: the lower the grain size, the higher is the intergranular resistance. Nevertheless, nanoscaled thin layers may also have a beneficial impact on electrode reaction mechanisms, on thermal constraints and on cost reduction. New architectures, which include thin layers, 
appear capital for the efficient development of SOFC technology. Recently, several thin layers techniques have been dedicated to SOFCs devices, as described in an interesting paper, focussing on vacuum deposition or liquid-based techniques [7].

This work is dedicated to the optimisation of thin layers obtained by different techniques (dip-coating, sputtering and atomic layer deposition), to analyse their performance and compare them in different configurations. Our final goal is to use anode-supported cells, but as a first step, in order to optimise the cathode interfaces, we have concentrated our effort on the interfaces between YSZ electrolyte and LSM cathode. In the present paper, the first of a series of three papers, our purpose is to analyse the effect of an interfacial layer of YSZ $(80 \mathrm{~nm})$ deposited by the above-mentioned techniques and covered by a thick LSM layer deposited by painting. After depositing and characterising the structural and morphological properties of these layers, the main focus is given to the electrical and electrochemical behaviour of such systems including the mentioned ultrathin layers. One must keep in mind that this part aims essentially at comparing the techniques operated at given elaboration conditions and does not constitute a final goal. The originality is also in the variety of the thin layers developed in three independent laboratories; moreover, in order to have a rigorous comparison of the electrical properties of all the systems including such thin layers, all the impedance spectroscopy tests were realised in the same entity. As the knowledge of the specific behaviour of thin layers properties is still relatively poor, our contribution makes sense and will allow, at least, pointing out some crucial facts concerning nanoorganised interfaces.

\section{EXPERIMENTAL}

Ultrathin layers of $80 \mathrm{~nm}$ were elaborated by three techniques in different laboratories:

At the CIRIMAT by dip-coating.

At the LSGS by reactive sputtering (PVD).

At the LECIME by atomic layer deposition (ALD).

Impedance spectroscopy measurements were realised at the LECIME.

Thick contact layers were deposited by painting at the ICMCB.

\subsection{Preparation of Electrolyte Substrates}

The electrolyte substrates were prepared from an YSZ commercial powder containing $8 \mathrm{~mol} \%$ of $\mathrm{Y}_{2} \mathrm{O}_{3}$ (TZ8Y from Tosoh Corp, Japan). The powder was pressed into pellets of diameter $19 \mathrm{~mm}$ and thickness of around $1 \mathrm{~mm}$. They were sintered at $1350{ }^{\circ} \mathrm{C}$ for $2 \mathrm{~h}$ in air. After sintering, density of the pellet was up to $95 \%$. Pellets were then polished mirror-quality with an average roughness of about 10-15 nm and then cleaned in successive ultrasonic baths of acetone and alcohol.

\subsection{Preparation of Precursor and Deposition of YSZ Thin Film with Different Techniques}

\section{2.a. Thin Yttria-Stabilised Zirconia Deposited by Atomic Layer Deposition (ALD)}

Thin films $(80 \mathrm{~nm})$ were deposited in a commercial flowtype hot-wall ALD reactor F-120 manufactured by ASM
Microchemistry Ltd. Film depositions were carried out at 1-3 mbar pressure. Commercial $\mathrm{Cp}_{2} \mathrm{ZrCl}_{2}$ (Strem Chemicals, \#93-4002, 99\%) was used as the zirconium precursor and Y(thd) $)_{3}$ (Strem Chemicals, \#39-1000, 98+\% (99.9\%-Y)) was used as the yttrium precursor. $\mathrm{O}_{3}$ was used as oxidizer and it was generated from $\mathrm{O}_{2}(99.999 \%)$ in an ozone generator (Fischer model $500 \mathrm{MM})$. Nitrogen $(>99.999 \%$, Schmidlin UHPN $3000 \mathrm{~N}_{2}$ generator) was used as carrier and purging gas. Pulsing lengths varied between 1 and $2.5 \mathrm{~s}$.

The standard pulsing sequence in one cycle combines two pulsing sequences of $\mathrm{Cp}_{2} \mathrm{ZrCl}_{2}$ (Pulses 1-4) followed by one pulsing sequence of $\mathrm{Y}(\mathrm{thd})_{3}$ (Pulses 5-8). The number of deposition cycles determines the film thickness.

Pulse1: $\mathrm{Cp}_{2} \mathrm{ZrCl}_{2}$ for $1 \mathrm{~s}$

Pulse 2: $\mathrm{N}_{2}$ purge for $1 \mathrm{~s}$

Pulse 3: $\mathrm{O}_{3}$ for $2.5 \mathrm{~s}$

Pulse 4: $\mathrm{N}_{2}$ purge for $1 \mathrm{~s}$

Pulse 5: $\mathrm{Y}(\text { thd })_{3}$ for $1 \mathrm{~s}$

Pulse 6: $\mathrm{N}_{2}$ purge for $1 \mathrm{~s}$

Pulse 7: $\mathrm{O}_{3}$ for $2.5 \mathrm{~s}$

Pulse 8: $\mathrm{N}_{2}$ purge for $1 \mathrm{~s}$

The deposition temperature was $300^{\circ} \mathrm{C}$. The volatilisation temperatures of precursors were the following: $120^{\circ} \mathrm{C}$ for $\mathrm{Y}(\mathrm{thd})_{3}$ and $130^{\circ} \mathrm{C}$ for $\mathrm{Cp}_{2} \mathrm{ZrCl}_{2}$. The microstructure and the film thicknesses were evaluated from scanning electron microscopy (SEM) micrographs; an example is given in Fig. (1a, b).

\section{2.b. Thin Yttria-Stabilised Zirconia Deposited by Sputtering (PVD)}

80 nm-thick YSZ films were deposited at room temperature by sputtering a 16 at $\% \mathrm{Y}-\mathrm{Zr}$ target in a reactive $\mathrm{Ar}-\mathrm{O}_{2}$ atmosphere. The experimental device is a 40-litre sputtering chamber pumped down via turbo-molecular pump, allowing a base vacuum of $10^{-4} \mathrm{~Pa}$. The $50 \mathrm{~mm}$ in diameter target was fixed on an unbalanced magnetron with its centre at $60 \mathrm{~mm}$ from the rotating substrate-holder axis. It was powered by an Advanced Energy system consisting of a $6 \mathrm{~kW}$ Pinnacle D.C. unit connected to a $20 \mathrm{kHz}$ Spark-le pulser operated in active arc mode. The YSZ bulk pellets were placed with their centre at $40 \mathrm{~mm}$ from the holder axis. The argon and oxygen flow rates controlled with MKS flowmeters were set to 25 and $2.6 \mathrm{sccm}$ respectively to run the process in the compound sputtering regime. The argon pressure measured using a MKS Baratron absolute gauge was close to $0.3 \mathrm{~Pa}$. Before the deposition, a $50 \mathrm{~W}$ radiofrequency plasma etching procedure was applied for 5 minutes to the YSZ substrate in order to create free radicals and consequently improve the film adhesion. This procedure was ended few seconds after the start of the deposition run. The discharge current during the deposition run was fixed to $0.5 \mathrm{~A}$, the resulting discharge voltage was close to $320 \mathrm{~V}$.

\section{2.c. Thin Yttria-Stabilised Zirconia Deposited by Dip- Coating}

Yttria stabilized zirconia precursor sols were prepared in the system consisting of zirconium n-propoxide, yttrium nitrate, n-propanol, acetylacetone $(\mathrm{acacH})$ and water. 

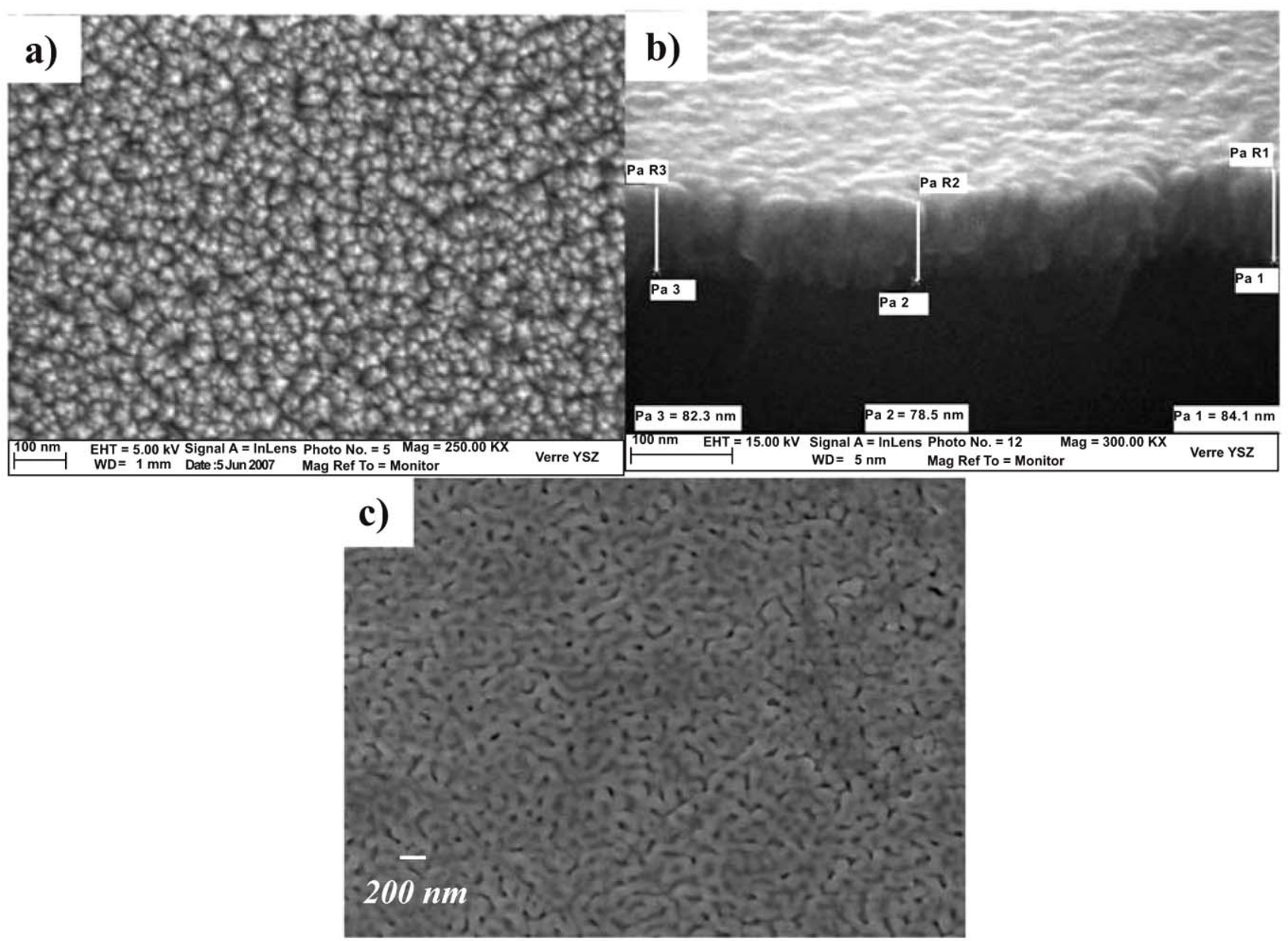

Fig. (1). SEM micrographs relative to YSZ thin layers deposited by ALD onto soda-lime glass (a) surface morphology, (b) cross-section and (c) surface morphology deposited by dip-coating onto YSZ substrate.

Commercial zirconium alkoxide (Aldrich \#33,397-2, $70 \mathrm{wt} \%$ solution in 1-Propanol), yttriumIII nitrate hexahydrate (Acros Organics \#13494-98-9, 99.9\%), 1-Propanol (Acros Organics \#71-23-8, +99\%), acetylacetone (Sigma-Aldrich \#P775-4, +99\%) and deionised water were used as starting precursors. Zirconium alkoxide being very reactive with water, the zirconium n-propoxide was first diluted with npropanol and then chelated by acetylacetone under neutral atmosphere, which allows controlling the hydrolysis and condensation reactions avoiding precipitation [13-14]. Then, a water/n-propanol mixture containing the yttrium salts, previously dissolved, was added under vigorous mechanical stirring. The zirconium n-propoxide concentration $\mathrm{C}=[\mathrm{Zr}$ $\left.\left(\mathrm{OC}_{3} \mathrm{H}_{7}\right)_{4}\right]$ was kept equal to $0.5 \mathrm{~mol} / \mathrm{L}$, the hydrolysis and complexing ratios being kept constant, $W^{\prime}=\left[\mathrm{H}_{2} \mathrm{O}\right] /\left[\mathrm{Zr}\left(\mathrm{OC}_{3}\right.\right.$ $\left.\left.\mathrm{H}_{7}\right)_{4}+\mathrm{Y}\left(\mathrm{NO}_{3}\right)_{3}-6 \mathrm{H}_{2} \mathrm{O}\right]=10 \quad$ and $\quad \mathrm{R}^{\prime}=[\mathrm{acacH}] /\left[\mathrm{Zr}\left(\mathrm{OC}_{3} \mathrm{H}_{7}\right)_{4}+\right.$ $\left.\mathrm{Y}\left(\mathrm{NO}_{3}\right)_{3}-6 \mathrm{H}_{2} \mathrm{O}\right]=0.7$ respectively. The obtained sols are homogeneous, clear and transparent.

After dipping the YSZ polycrystalline polished mirror substrate into the sol and after withdrawing it at a controlled speed, a coating of yttria stabilized zirconia precursor sol was carried out under ambient conditions. During the dipping, the liquid film ran out on the substrate, adhered to its surface and the solvents evaporation led to its rapid consolidation. In the dip-coating process, the as-prepared coating thickness is mainly depending on various synthesis and shaping parameters as the sol viscosity and density, the liquid-vapor surface tension and the withdrawal speed. Its behaviour generally evolves by a relationship derived by Landau and Levich [15]. The final thickness of the annealed coating also relies on the solid content, i.e. the zirconium alkoxide concentration and the annealing temperature. In this work, the synthesis sol parameters were kept constant in order to adjust the final thickness layer at $80 \mathrm{~nm}$. So, the only adjustable parameter was the withdrawal speed which was kept at $1.8 \mathrm{~cm} / \mathrm{min}$. After a drying at $60^{\circ} \mathrm{C}$ during 20 minutes, the films were continuous, homogeneous and crack free as observed by optical microscopy. The dried films were thermal treated in an electric furnace at a rate of $100^{\circ} \mathrm{C} / \mathrm{h}$ up to $1000^{\circ} \mathrm{C}$ with a two hours dwell time. X-ray diffraction measurements show after thermal treatment at $1000^{\circ} \mathrm{C}$, the crystallisation of the precursor in the cubic yttria-stabilised zirconia phase. The relative intensities of the peaks being in good agreement with JCPDS files, the cubic yttria-stabilized zirconia crystals are randomly orientated. The in situ homogeneous crystallisation of the zirconia precursor led to relatively dense layer at $1000^{\circ} \mathrm{C}$ and constituted of a very narrow distribution of crystallised YSZ nanoparticle sizes $(70 \mathrm{~nm})$ as it can be seen in Fig. (1c). 


\subsection{Deposition of $\mathrm{La}_{0.8} \mathrm{Sr}_{0.2} \mathrm{MnO}_{3}$ Cathode}

Commercial submicronic powders were used for lanthanum strontium manganite cathode (LSM powder $(20 \%$ strontium) from Nextech Materials Co. Ltd.). Cathode ink was prepared mixing the powder with ethanol or ethylene glycol. The slurry was painted onto the thin interlayer of YSZ by means of a brush. The green layer was annealed in air at $1200^{\circ} \mathrm{C}$ for $2 \mathrm{~h}$ to obtain a strong adhesion between the components. The whole electrode thickness was about 10-13 $\mu \mathrm{m}$.

\subsection{Morphological and Structural Analysis}

The surface morphology and the microstructure of the cross-section of the samples were investigated using scanning electron microscope SEM (S440, FEG from LEICA). The thickness of the deposits was determined from cross-sectional SEM micrographs. Surface and cross sectional images were obtained from the samples YSZ/YSZ(dip-coating)/LSM, YSZ/YSZ(PVD)/LSM and YSZ/YSZ(ALD)/LSM. An X-ray diffraction analysis was assessed on the sputtered film using a Co $\mathrm{K}_{\alpha}$ radiation $(\lambda=$ $0.178897 \mathrm{~nm}$ ) in glancing angle condition $\left(2^{\circ}\right)$.

\subsection{Electrical Measurements}

Electrical measurements were performed by impedance spectroscopy, using a PGSTAT 20 potentiostat, Autolab Ecochemie BV. (Amsterdam, the Netherlands). Impedance spectroscopy measurements were carried out under ambient atmospheric air, as a function of the temperature. A specific two-electrodes asymmetric configuration was used as depicted in Fig. (2) [4]. Even if non-ideal, this electrochemical configuration, with a Pt point electrode, was used for all the samples. It allows a reasonable comparison of their properties in similar conditions. With respect to the system linearity, $50 \mathrm{mV}$ ac signal amplitude was applied, without DC polarisation. Each impedance measurement was carried out in the $1 \mathrm{MHz}-10 \mathrm{mHz}$ frequency range, with 11 points per decade. The temperatures varied from $390^{\circ} \mathrm{C}$ to $700^{\circ} \mathrm{C}$. The numbers shown in the impedance diagrams indicate the logarithm of the measuring frequency. The impedance data are deconvoluted using the software EQUIVCRT [16].

\section{RESULTS AND DISCUSSION}

\subsection{Morphological and Structural Analysis}

Fig. (3) shows the surface morphology and the crosssection of the fractured surface for the three samples, including the YSZ interfacial layer deposited by dip-coating, ALD or PVD. The LSM thick films adhered well to the dense electrolyte. An homogeneous distribution of pores and particles can be observed over the whole LSM thickness. Although the thick cathode layers were sintered at the same temperature $\left(1200^{\circ} \mathrm{C}\right.$ for 2 hours), their microstructure was slightly different (Fig. 3b, d, f). The origin of such modification is difficult to elucidate: it does not seem likely to be due to a difference in the surface state of the thin YSZ layer $(80 \mathrm{~nm})$ over which is deposited the thick layer of LSM cathode. No precise explanation can be given at this stage, apart maybe the chemical reactivity between both layers, which may be influenced by the YSZ deposition technique. For all the samples, the dense YSZ substrate is clearly visible and it is possible to distinguish the porous from the dense phase (Fig. 3a, c, e). The thicknesses of LSM, determined from the SEM, micrograph are in the range of 10 to $13 \mu \mathrm{m}$.

In order to estimate the thickness and the average grain size of the YSZ(ALD) layer, the film was deposited in the same conditions on soda-lime glass (Fig. 1a, b); the particles size of the deposited YSZ is around 18-25 nm and the thickness of the thin layer is in the range of 78-84 nm. In the case of the YSZ(PVD) layer, the film was deposited in the same conditions on an amorphous substrate, soda-lime glass, and a crystalline isostructural one, ceria-doped gadolinia (CGO). The X-ray diffraction patterns of the film deposited on soda-lime glass is presented in Fig. (4). Broad diffraction peaks characteristic of YSZ are present (JCPDS, ref. 301468). The average grain size was estimated from the Scherrer formula in the range of 7-11 nm, either on glass or

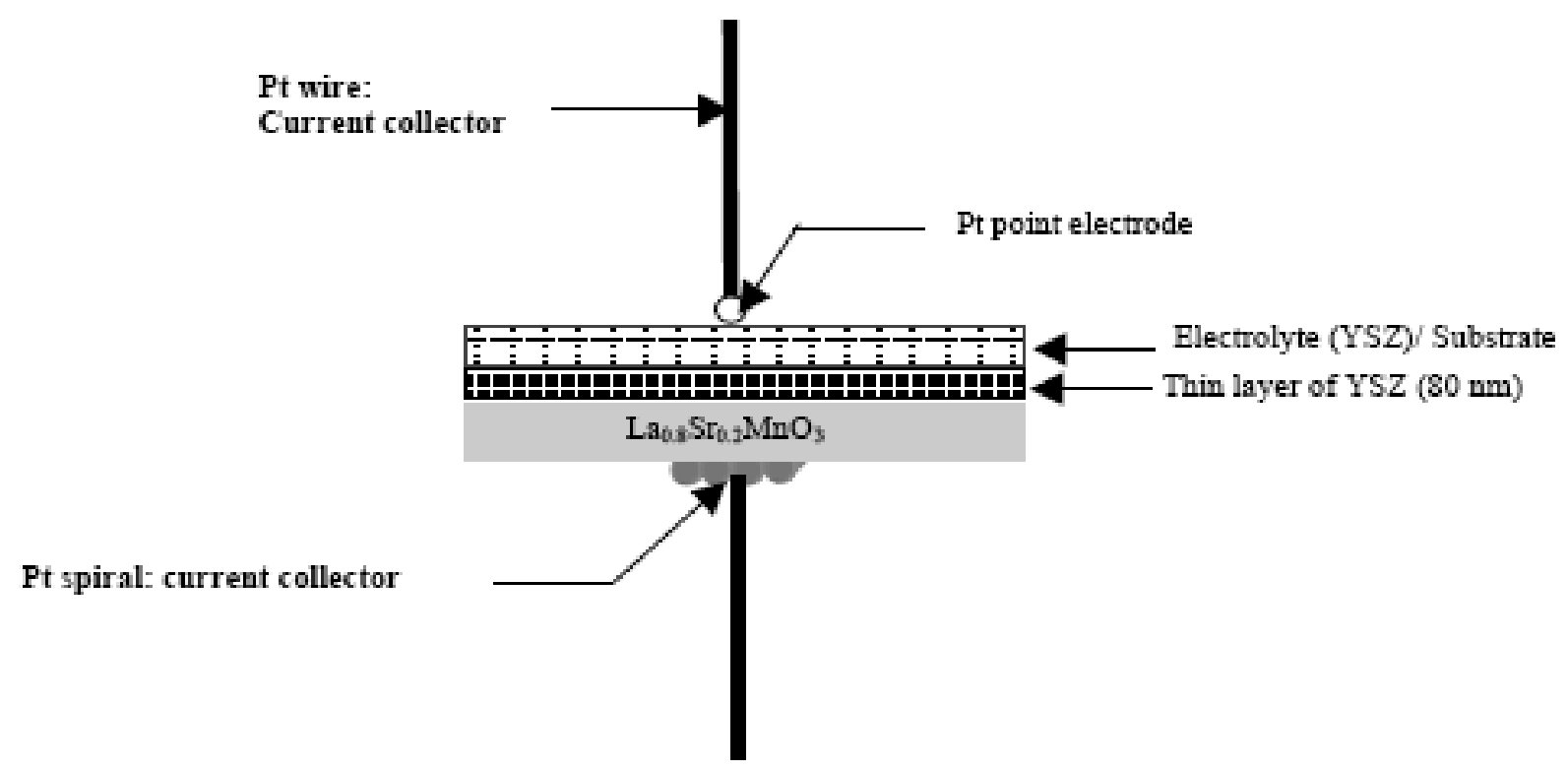

Fig. (2). Scheme of the measurement device used for the impedance spectroscopy measurements [4]. 


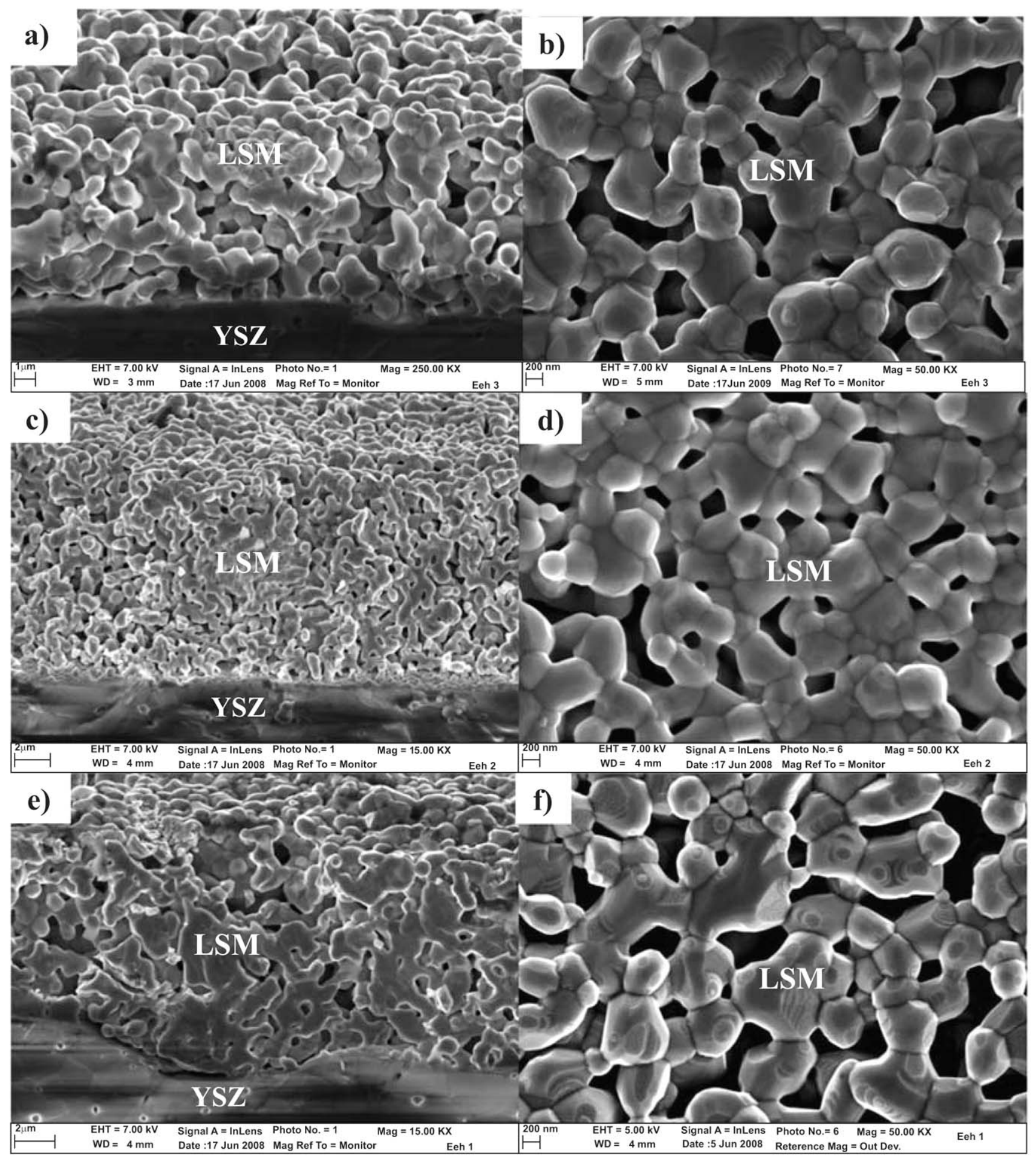

Fig. (3). SEM micrographs relative to surface morphology and cross-section of (a, b) YSZ/YSZ(dip-coating)/LSM (c, d) YSZ/YSZ(PVD)/LSM and e,f) YSZ/YSZ(ALD)/LSM samples.

CGO substrates [17], which highlights the very limited influence of the substrate chemical and structural state within the deposition conditions explored in the present study. The thickness of the coatings was obtained by fitting the interferometric measurements obtained by Optical Transmission Interferometry (OTI) with a simple Matlab simulation program, following a theory developed elsewhere
[18-20]. Coating thickness was also determined ex-situ by optical transmittance measurements performed with a UVvisible-NIR Carry 5000 Varian Spectrophotometer, using a software developed at the laboratory with the assistance of PVDco (a French SME). These measurements were systematically confirmed using the step method with a Talysurf profilometer. 


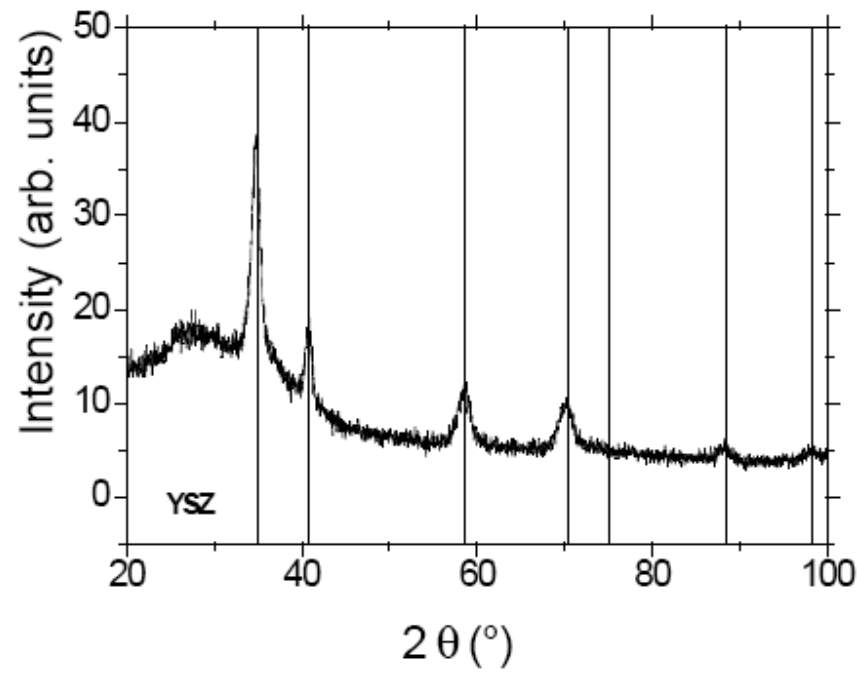

Fig. (4). X-ray diffractogramm of an $80 \mathrm{~nm}$ YSZ layer deposited on soda-lime glass substrate. The vertical lines represent the theoretical positions of the YSZ diffraction peaks.

The YSZ thin film layers deposited by dip-coating, PVD or ALD between the YSZ substrate and the LSM thick film are shown in some detail in Fig. (5). According to the SEM migrographs, there is a difference between the thin layer of YSZ deposited by PVD and the two other techniques. The thin layer is more visible and well-bonded to the YSZ substrate when it deposited by ALD or dip-coating. The YSZ interlayer prepared from PVD is not clearly visible and has probably reacted with the LSM layer. It is well known that the fine electrode microstructure close to the electrolyte would induce a large triple phase boundary (TPB) length and facilitate the charge transfer reaction and the coarser microstructure and porosity of the thicker outer cathode layer would facilitate the gas transport. For the YSZ thin layer deposited by ALD, fine particles of LSM are observed near the interlayer. This can be explained by the effect of the YSZ interlayer surface on the morphology of the LSM layer when it is coated.

\subsection{Impedance Diagrams}

The impedance responses measured at low and high temperature for the different cathode/electrolyte systems are presented in Figs $(\mathbf{6}, 7)$, respectively. The impedance diagram shapes are different. At low temperature, the semicircle observed at the high frequency range is well-defined (i.e. up to $10 \mathrm{kHz}$ at $450^{\circ} \mathrm{C}$ ) for the three samples, but at the
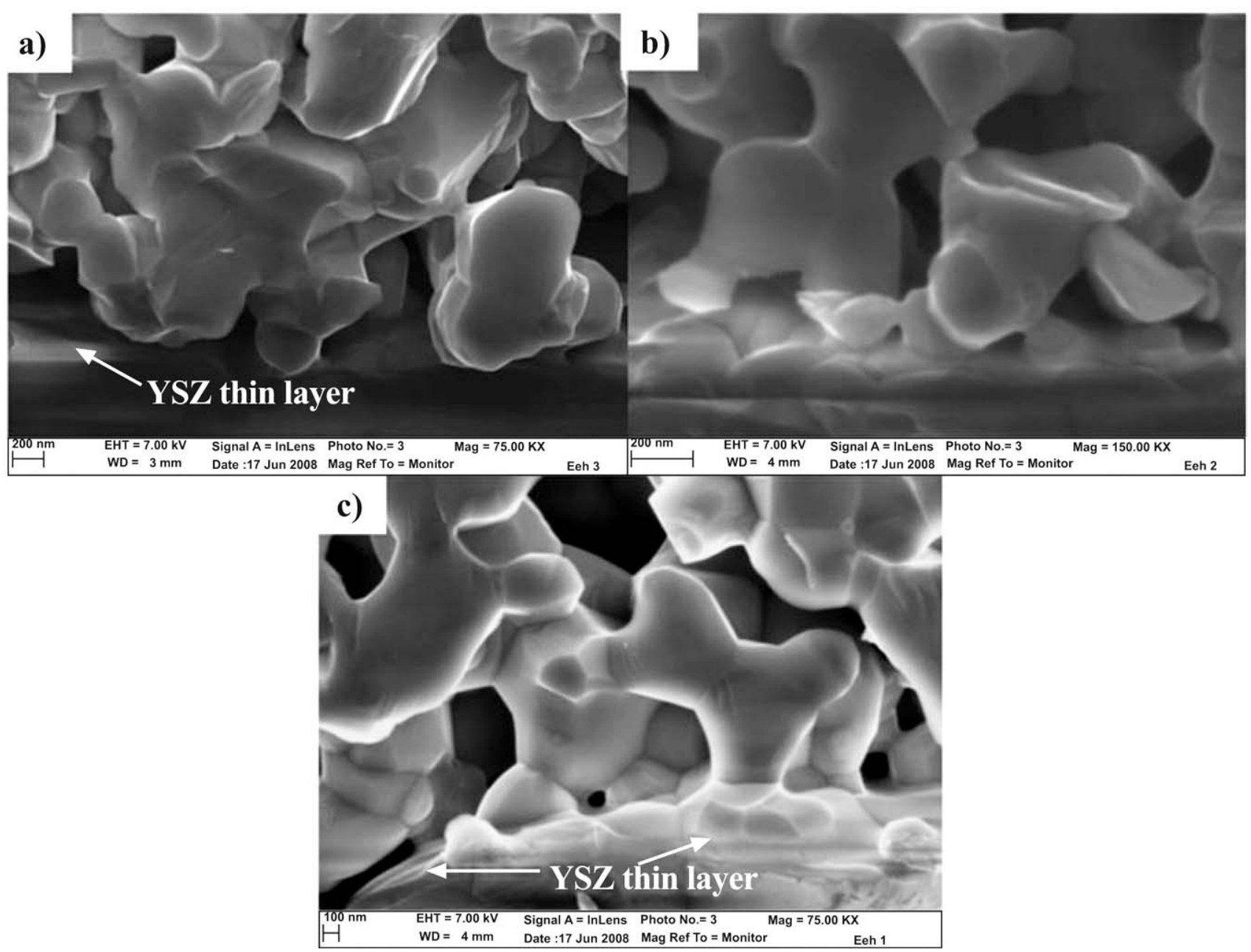

Fig. (5). SEM micrographs of the cross-sections of (a) YSZ/YSZ(dip-coating)/LSM (b) YSZ/YSZ(PVD)/LSM and (c) YSZ/YSZ(ALD)/LSM samples. 


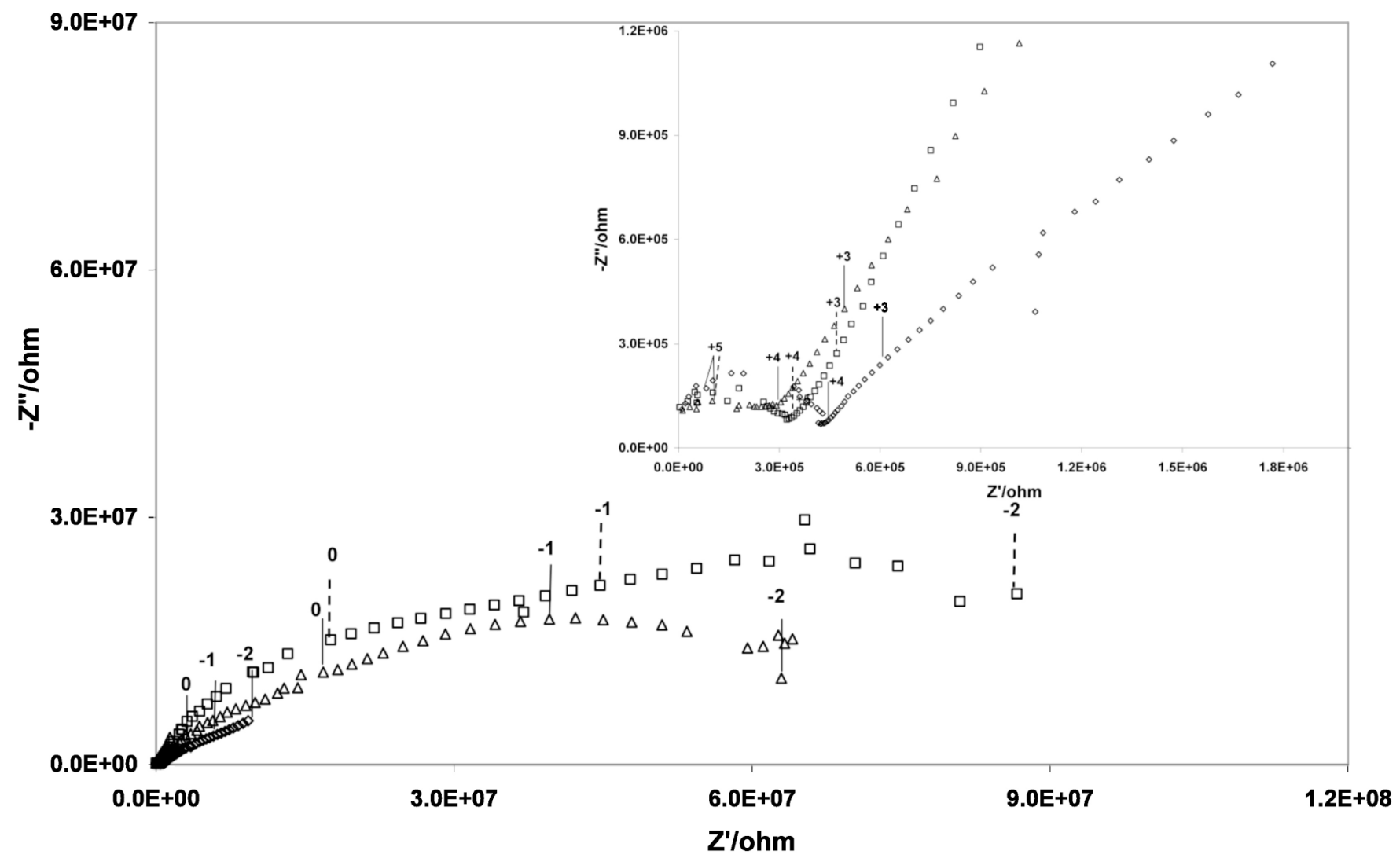

Fig. (6). Impedance diagrams measured at $450{ }^{\circ} \mathrm{C}$ for $\Delta$ )YSZ/YSZ (PVD)/LSM, $\square$ )YSZ/YSZ(dip-coating)/LSM and $\left.\diamond\right) Y S Z / Y S Z$ (ALD)/LSM. Frequency logarithms are indicated.

lowest frequencies the responses are not fully defined in the frequency range used. The sample with the YSZ thin film deposited by ALD presents a higher resistance at high frequencies compared to the two other samples. At high temperature, the impedance spectra have a different shape. The first semi-circle, in the high frequency range, becomes smaller (i.e. up to $100 \mathrm{kHz}$ at $660^{\circ} \mathrm{C}$ ), whereas, the responses at medium and low frequencies become predominant. In the Bode diagram (Fig. 7b), three phenomena can be observed at high, medium and low frequencies. The samples with the interlayer prepared by dip-coating and PVD have the same shapes with a small response for the phenomenon appearing at medium frequencies $(100-0.5 \mathrm{kHz})$ and a large and predominant response for the phenomenon observed at low frequencies $(500-0.01 \mathrm{~Hz})$. Contrarily, the sample with YSZ (ALD) layer has a large response at medium frequencies (50$0.01 \mathrm{kHz}$ ).

The best equivalent circuit fitting comprises a series of three parallel combinations of resistance and a constant phase element, $\mathrm{CPE}$, as shown in Fig. (8). In the circuit, $\mathrm{R}_{\mathrm{HF}}$ is the ohmic resistance of the electrolyte, $\mathrm{R}_{\mathrm{MF}}$ and $\mathrm{R}_{\mathrm{LF}}$ related to the electrode interface resistances at medium and low frequencies. $\mathrm{CPE}_{\mathrm{MF}}$ and $\mathrm{CPE}_{\mathrm{LF}}$ are the corresponding constant phase elements. CPE is an admittance $\mathrm{Y}=\mathrm{Y}_{0}(\mathrm{j} \omega)^{\mathrm{n}}$, where $\mathrm{n}$ is the frequency exponent and $\omega$ is the angular frequency. The arc summit frequencies were calculated using the formula $f^{\circ}=1 /\left(2 \pi\left(R Y_{0}\right)^{1 / n}\right)$ and associated capacitances using the formula $C=1 /\left(2 \pi R f^{\circ}\right)$, where $\mathrm{f}^{0}$ is the relaxation frequency [21].
The selected circuit was used to fit the observed impedance diagrams. An example on the YSZ/YSZ(dipcoating)/LSM sample is shown in Fig. (9). In this figure, the symbols are the experimental data and the lines are the fitted values using the equivalent circuit of Fig. (8). The fittings between the experimental data and the calculated data are generally good. The error in the resistance evaluated by the software (EQUIVCRT) was $\pm 3 \%$.

The high frequency semicircles, HF, were attributed to the YSZ electrolyte. The response of the electrolyte corresponds to both YSZ substrate and YSZ thin film deposited by ALD, dip coating or sputtering. The capacitances relative to the high frequency phenomenon (Fig. 11) are in the order of $10^{-12}-10^{-11} \mathrm{~F}$, showing no significant influence of the thin layer of YSZ.

Arrhenius plots of the electrolyte conductivity are shown in Fig. (10). The activation energies deduced from the Arrhenius relation, are given in Table $\mathbf{1}$.

The activation energies of the electrolyte response (HF) for the different cathode/electrolyte systems, determined from the Arrhenius diagrams, are almost the same, showing again the weak influence of the YSZ thin layer. The values are between 1.12 and $1.17 \mathrm{eV}$. These results are in agreement with the values reported in the literature [22]. However, it can be noted that the conductivity of the YSZ/YSZ(ALD) layer is slightly lower than that corresponding to the other systems. 

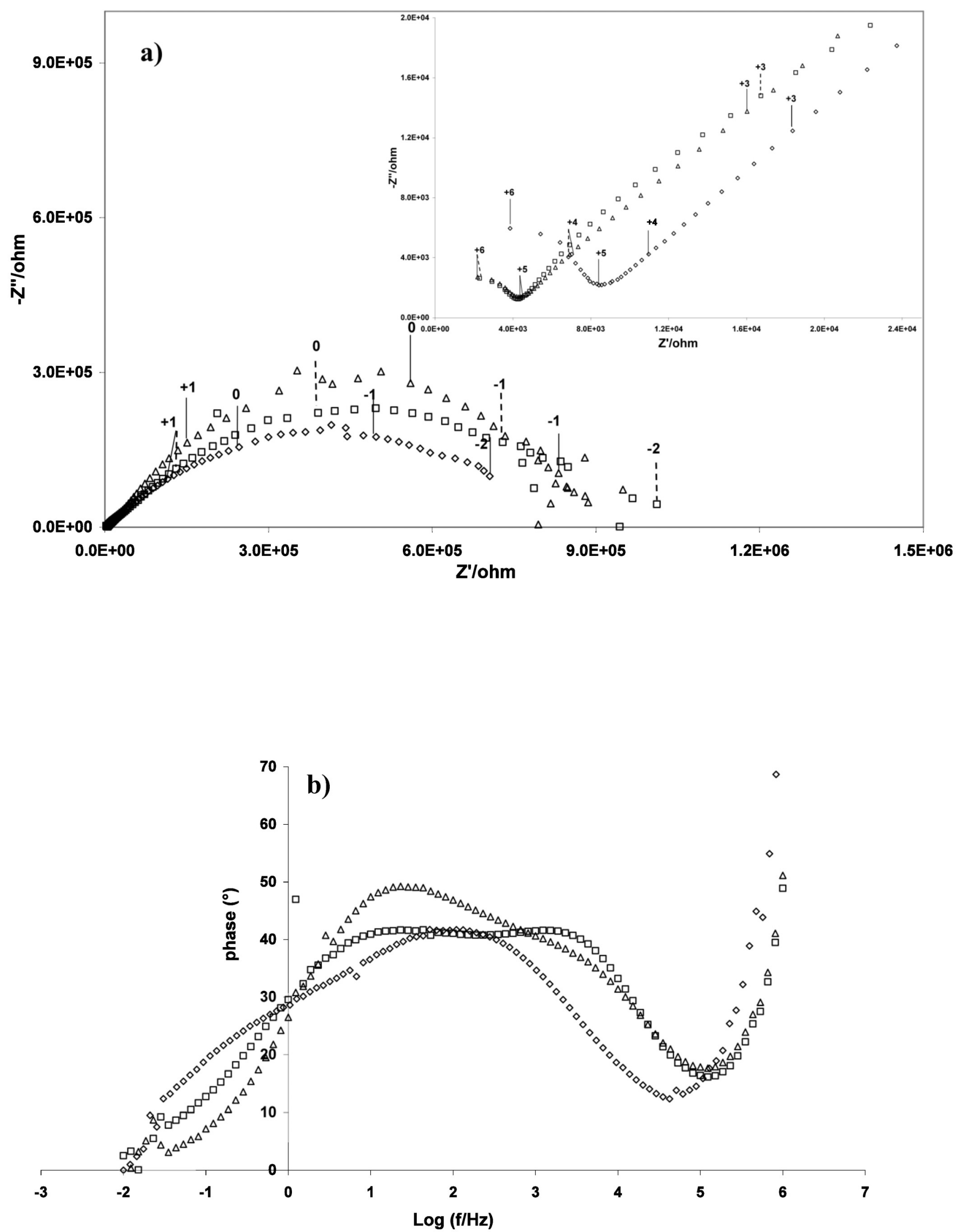

Fig. (7). Impedance diagrams measured at $660{ }^{\circ} \mathrm{C}$ for $\left.\Delta\right) Y S Z / Y S Z$ (PVD)/LSM, $\square$ )YSZ/YSZ(dip-coating)/LSM and

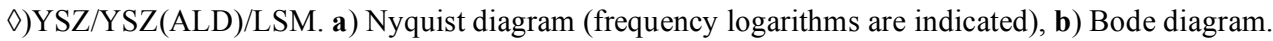




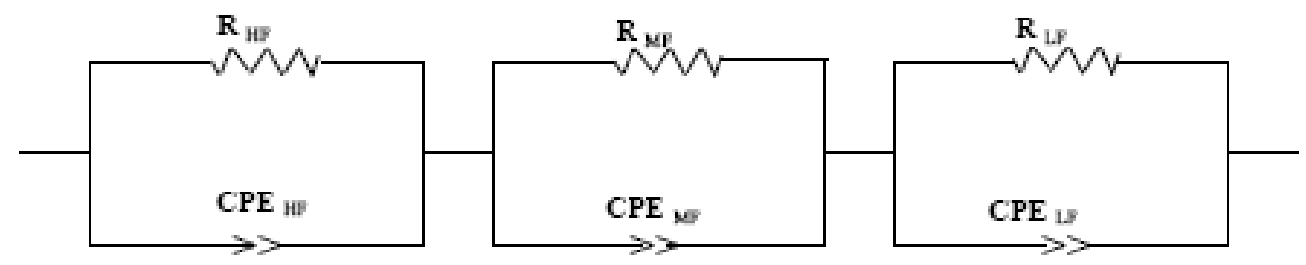

Fig. (8). Equivalent circuit used for fitting Impedance diagrams of samples.
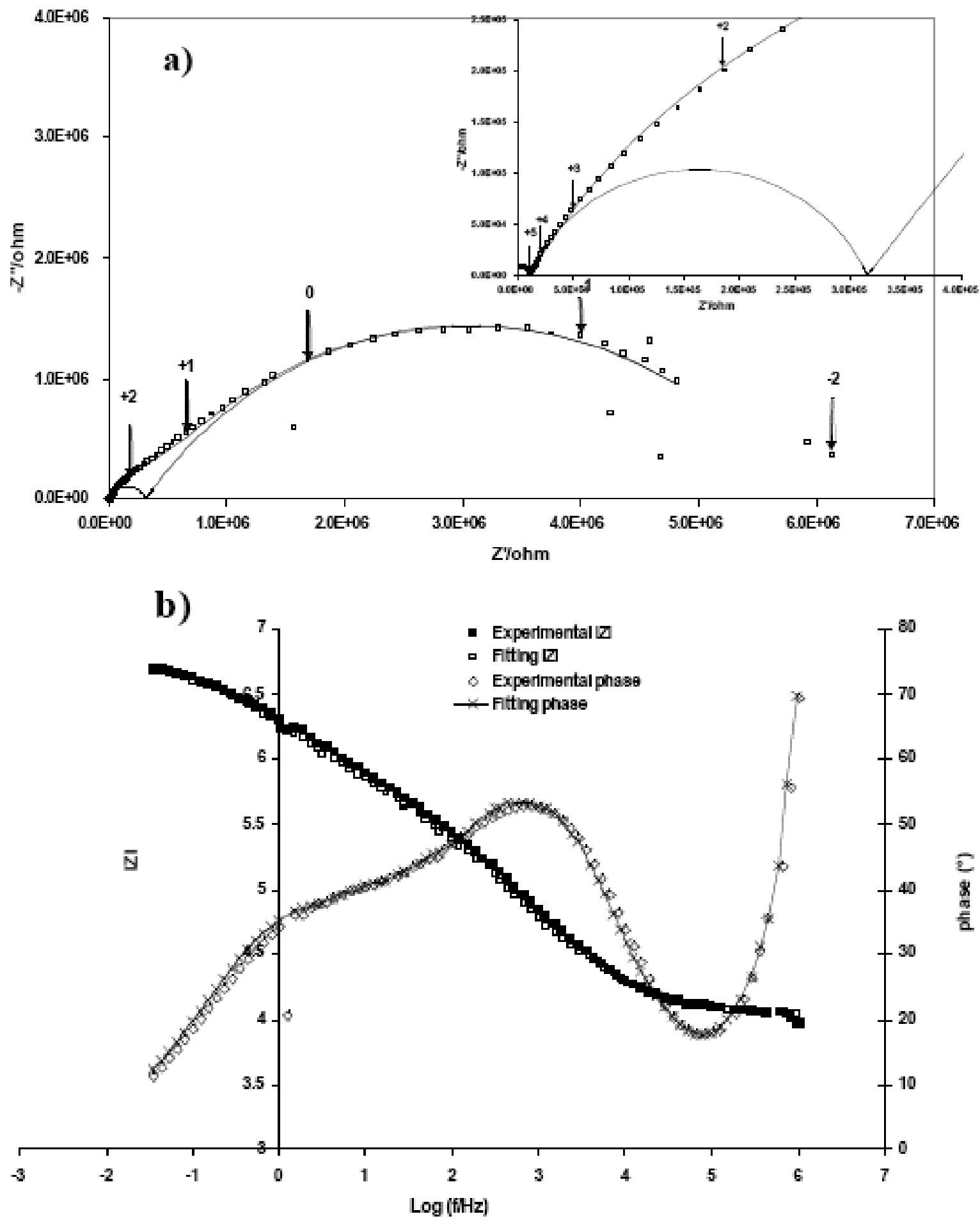

Fig. (9). Fitted results of experimental data measured at $600{ }^{\circ} \mathrm{C}$ for YSZ/YSZ(dip-coating)/LSM sample. ( $\square$ ) Experimental data; lines are the fitted results (a) Nyquist diagram and (b) Bode diagram. 


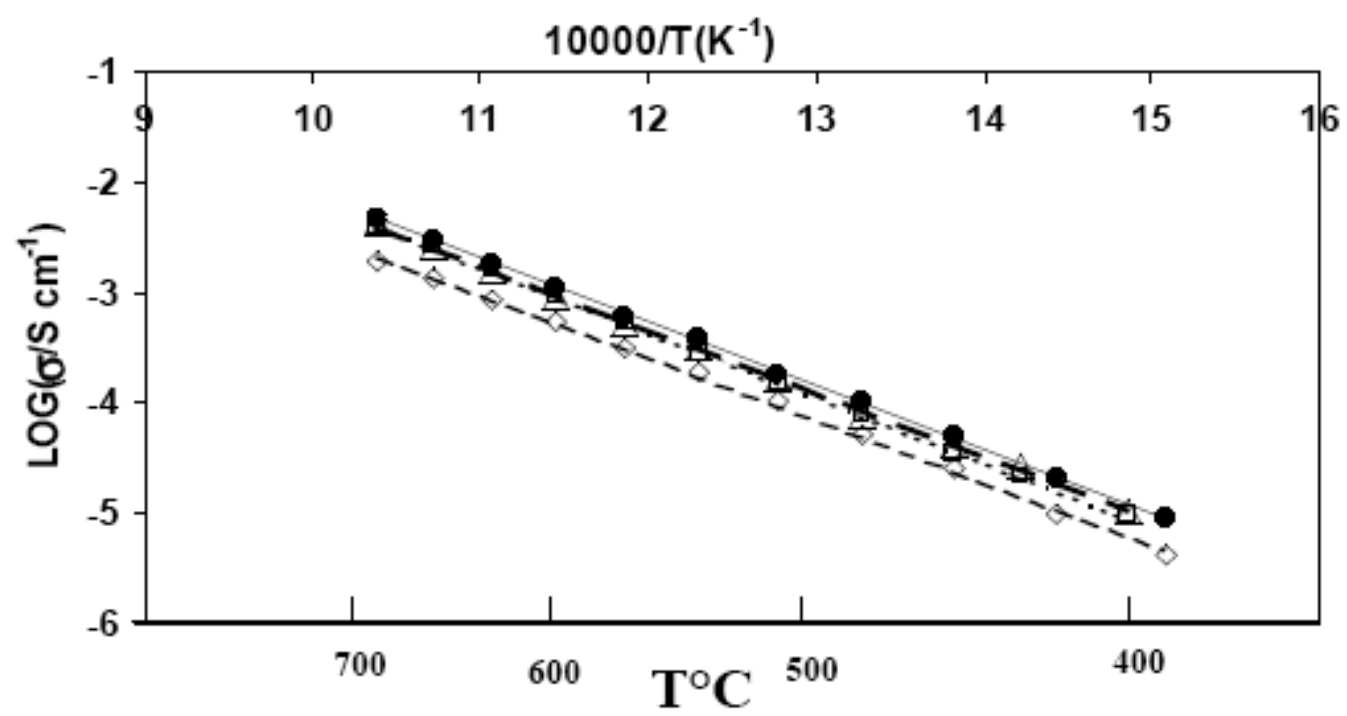

Fig. (10). Arrhenius plots of the electrolyte conductivity (HF) for $\Delta$ ) YSZ/YSZ(PVD)/LSM, $\square$ ) YSZ/YSZ(dip-coating)/LSM, $\diamond$ ) YSZ/YSZ(ALD)/LSM and •) YSZ/Pt.

Table 1. The Activation Energy of the Electrolyte Response (HF) for the Different Electrolyte /Cathode Systems

\begin{tabular}{|c|c|}
\hline Electrolyte/Cathode & Ea (eV) \\
\hline \hline YSZ/YSZ(PVD)/LSM & 1.14 \\
\hline YSZ/YSZ(dip coating)/LSM & 1.17 \\
\hline YSZ/YSZ(ALD)/LSM & 1.12 \\
\hline YSZ/Pt & 1.14 \\
\hline
\end{tabular}

The LSM electrode behaviour was characterised by two arcs at medium and low frequencies (Fig. 9). This indicates that $\mathrm{O}_{2}$ reduction on the LSM electrode is controlled by at least two different processes. The reaction mechanism of oxygen reduction involves a series of elementary reactions steps and still relatively little known. It is generally accepted that the overall reaction is composed of a multi-step reaction. In the literature [23-26], different interpretations were reported on the impedance behaviour of the electrode processes at medium frequencies $\left(\mathrm{O}_{2}\right.$ reduction reactions). Youngblood et al. [26] attributed the medium frequencies arc to the charge transfer process. Jiang et al. [23] associated the electrode processes at medium frequencies with the migration and diffusion of oxygen ions $\left(\mathrm{O}^{2-}\right)$ from the threephase boundary (TPB) region to the oxide ions vacancies located at the zirconia electrolyte lattice, the process being limited by the electrolyte conductivity. The semi-circle at medium frequency, $\mathrm{MF}$, represents 17 and $18 \%$ of the total electrode resistance at $450^{\circ} \mathrm{C}$ (low temperature) for the YSZ/YSZ(dip-coating)/LSM and YSZ/YSZ(PVD)/LSM systems, respectively. This ratio decreases, respectively, to 1 and $2 \%$ at $690^{\circ} \mathrm{C}$ (Fig. 12), which means that the impedance responses at low frequencies are more predominant at high temperature. This is not observed for the YSZ/YSZ (ALD)/LSM sample, where the ratio of the resistances $\mathrm{R}_{\mathrm{MF}} /\left(\mathrm{R}_{\mathrm{MF}}+\mathrm{R}_{\mathrm{LF}}\right)$ evolves very slightly with the temperature. The resistance MF represents about $10 \%$ of the total electrode resistance, whatever the temperature. There is generally a common consensus that the semicircle at lower

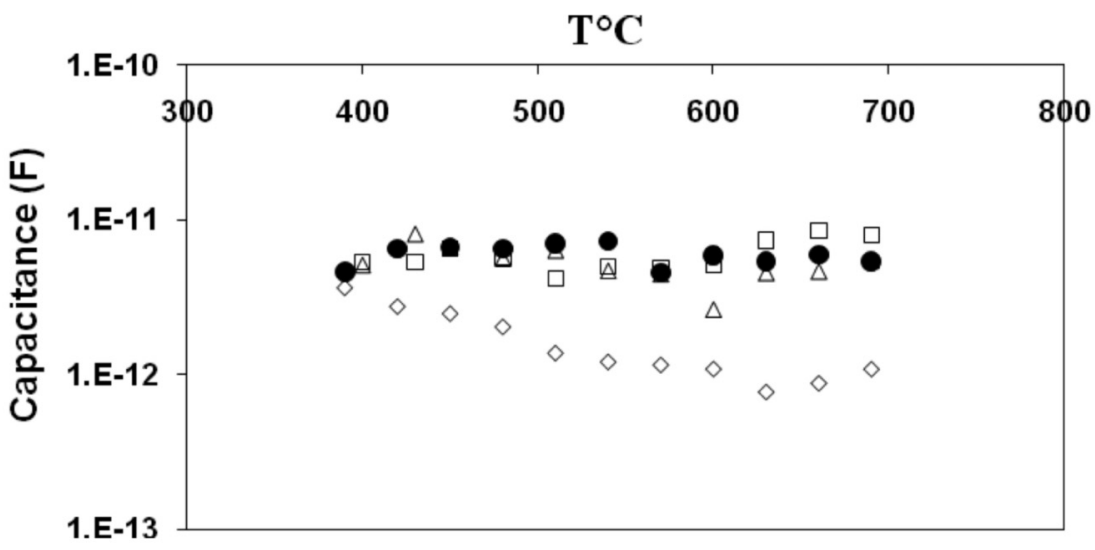

Fig. (11). Plots of the capacitance of the electrolyte response (HF) for $\Delta$ ) YSZ/YSZ(PVD)/LSM, $\square$ ) YSZ/YSZ(dip-coating)/LSM, $\diamond$ ) YSZ/YSZ(ALD)/LSM and •) YSZ/Pt. 


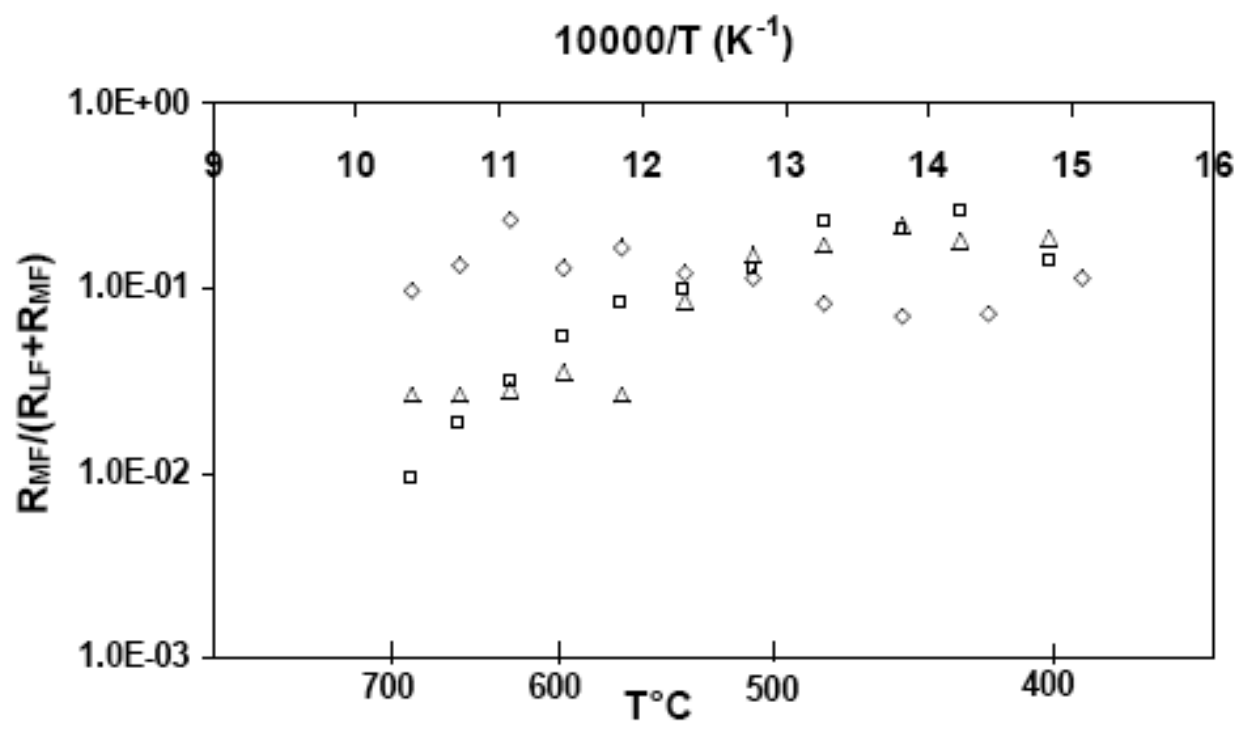

Fig. (12). Plots of the ratio $\left(\mathrm{R}_{\mathrm{MF}} /\left(\mathrm{R}_{\mathrm{MF}}+\mathrm{R}_{\mathrm{LF}}\right)\right.$ ) versus the temperature (HF) for $\Delta$ ) YSZ/YSZ(PVD)/LSM, $\square$ ) YSZ/YSZ(dip-coating)/LSM and $\diamond) Y S Z / Y S Z(A L D) / L S M$.

frequency, LF, is attributed to the dissociative adsorption and diffusion processes of oxygen on the porous LSM electrode surface. According to S.P. Jiang et al, the reaction steps of the electrode processes at the low frequency arc could be summarized as follows [25]:

Adsorption: $\frac{1}{2} O_{2(\text { gas })}+V_{O^{(L S M)}}^{. \cdot} \rightarrow O_{a d s(L S M)}$

Surface diffusion: $O_{a d s(L S M)} \rightarrow O_{a d s(L S M, T P B)}$

Charge transfer: $\mathrm{O}_{\text {ads (LSM,TPB })}+2 \mathrm{e}^{-} \rightarrow \mathrm{O}^{2-}$ (LSM,TPB)

Ionic transfer: $\mathrm{O}^{2-}{ }_{(\mathrm{LSM}, \mathrm{TPB})} \rightarrow \mathrm{O}^{2-}{ }_{(\mathrm{YSZ}, \mathrm{TPB})}$

The Arrhenius plots of the polarisation resistance as a fonction of the temperature for differents systems, depicted in Fig. (13), clearly shows that the YSZ/YSZ(ALD)/LSM system has the smallest polarisation resistances. The presence of the ALD-built YSZ interlayer improves the interfacial resistance of the LSM/YSZ system, despite a lower conductivity of the ionic system. This result clearly demonstrates that the polarisation resistance depends strongly on the thin interlayer nanostructure and on the intimate phase contacts between this thin layer and the cathode, which can be considered as the three-phase boundary, including the gas phase pores. Sasaki et al. [27] already suggested that the performance of the cathode is closely correlated to the length of the three-phase boundary (TPB). The change in the activation energy of the cathodic process for the three samples is difficult to explain and still not completely clear but indicates that a modification in the limiting step of the process occurs.

The activation energies relative to the electrode response are given in Table 2. Y. Jiang et al. [29] explained the

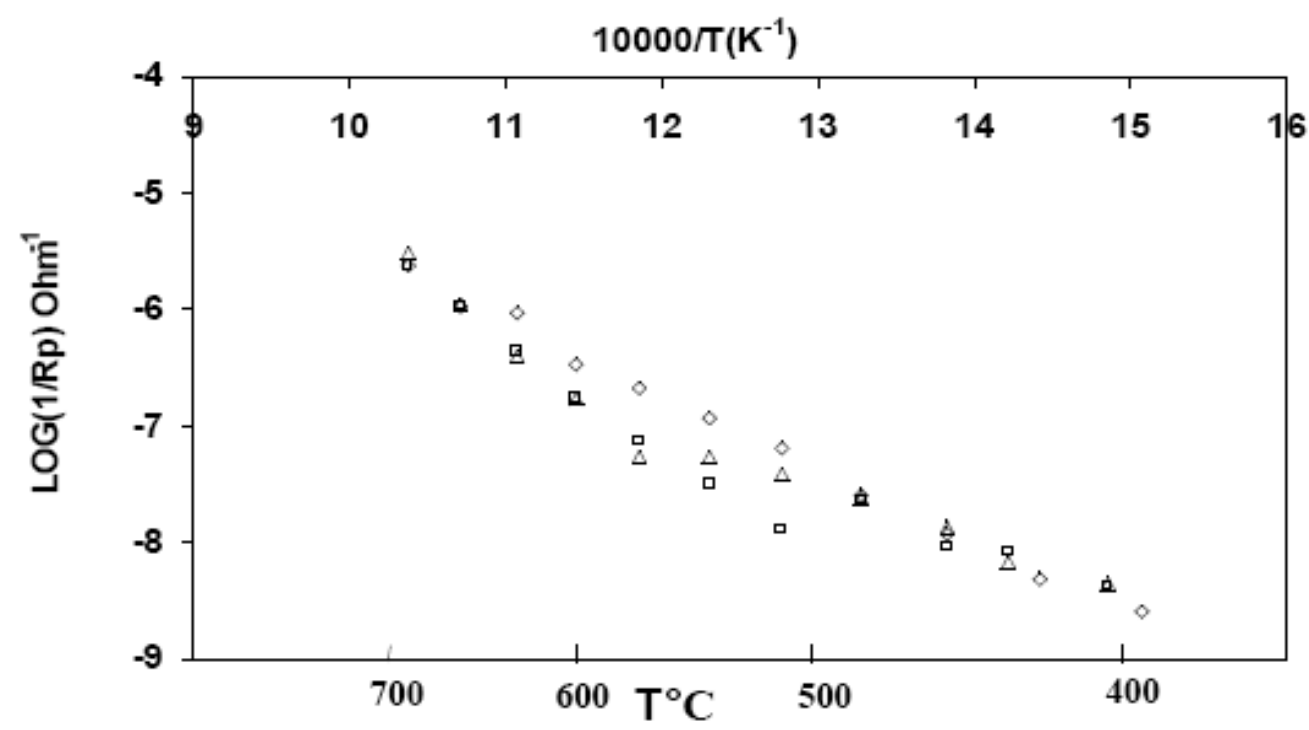

Fig. (13). Arrhenius plots of the polarisation resistance for $\Delta$ ) YSZ/YSZ(PVD)/LSM, $\square)$ YSZ/YSZ(dip-coating)/LSM and $\diamond)$ YSZ/YSZ(ALD)/LSM. 
Table 2. The Activation Energy of the Electrode Response (LSM) for the Different Electrolyte/Cathode Systems

\begin{tabular}{|c|c|c|c|c|}
\hline Electrolyte /Cathode & \multicolumn{2}{|c|}{$\mathbf{E a}(\mathrm{eV})$} & Ea (eV) Literature on LSM & [Refs.] \\
\hline YSZ/YSZ(PVD)/LSM & $\begin{array}{l}1.92 \\
1.00\end{array}$ & $\begin{array}{l}\mathrm{T}^{\circ} \geq 500{ }^{\circ} \mathrm{C} \\
\mathrm{T}^{\circ}<500{ }^{\circ} \mathrm{C}\end{array}$ & \multirow{2}{*}{$\begin{array}{l}1.61 \pm 0.05 \\
1.60 \mathrm{~T}^{\circ} \geq 700{ }^{\circ} \mathrm{C} \text { and } 1.24 \mathrm{~T}^{\circ}<700^{\circ} \mathrm{C} \\
1.99 \\
1.87 \\
1.20-2.00 \\
1.04\end{array}$} & \multirow{2}{*}{$\begin{array}{l}{[28]} \\
{[29]} \\
{[30]} \\
{[31]} \\
{[32]} \\
{[33]}\end{array}$} \\
\hline YSZ/YSZ(dip-coating)/LSM & $\begin{array}{l}1.92 \\
1.00\end{array}$ & $\begin{array}{l}\mathrm{T}^{\circ} \geq 550^{\circ} \mathrm{C} \\
\mathrm{T}^{\circ}<550{ }^{\circ} \mathrm{C}\end{array}$ & & \\
\hline
\end{tabular}

change in the activation energies between the high and low temperature region by the shift of the rate-determining step from one step to another as the temperature increases. It can be noted that the LSM electrode response reported in the literature presents values of activation energy between 1-2 $\mathrm{eV}$ as it can be see in Table 2, which is in agreement with those obtained in this study.

\section{CONCLUSIONS}

In this work, different techniques for preparing ultrathin YSZ interlayer were tested and used as a layer beaming for the thick layer of cathode deposited by painting. The micro, nanostructure and electrical conductive properties of YSZ/LSM system were investigated. This study demonstrated that the YSZ thin film deposited by dipcoating or ALD is more visible and well-bonded. However, The YSZ thin layer prepared from PVD is not clearly visible and has probably reacted with the LSM layer. The presence of a thin YSZ interlayer deposited by atomic layer deposition has a benefice effect of the interfacial resistance of the YSZ/LSM system compared to the thin YSZ interlayer deposited by dip-coating or sputtering. The electrical measurements by impedance spectroscopy showed that the activation energies of the YSZ electrolyte (including the pellet and the thin layer) are in agreement with that reported in the literature for bulk YSZ.

\section{ACKNOWLEDGEMENT}

This work was financed within the frame of the French CNRS (National Research Center for Scientific Research) programs (ACI-MICROSOFC). CNRS is warmly acknowledged by the authors.

\section{REFERENCES}

[1] Cassir, M.; Lincot, D.; Goubin, F. and Bernay, C.; French Patent (Renault) WO02053798, 2002.

[2] Gourba, E.; Briois, P.; Ringuedé, A.; Cassir, M.; Billard, A. Electrical properties of gadolinia doped ceria thin films deposited by sputtering in view of SOFC application. J. Solid State Electrochem., 2004, 8, 633-637.

[3] Briois, P.; Gourba, E.; Billard, A.; Ringuedé, A.; Cassir, M. Sputter-deposited electrolyte thin films for solid oxide fuel cells. Ionics, 2005, 11, 301-305.

[4] Brahim, C.; Ringuedé, A.; Gourba, E.; Cassir, M.; Billard, A.; Briois, P. Electrical properties of thin bilayered YSZ/CGO SOFC electrolyte elaborated by sputtering. J. Power Sources, 2006, 156, 45-49.

[5] Brahim, C.; Ringuedé, A.; Cassir, M.; Putkonen, M.; Niinistö, L. Electrical properties of thin yttria-stabilised zirconia overlayers produced by atomic layer deposition for solid oxide fuel cell applications. Appl. Surf. Sci., 2007, 253, 3962-3968.

[6] Brahim, C.; Ringuedé, A.; Cassir, M.; Putkonen, M.; Niinistö, L. Synthesis and properties of $\mathrm{ZrO}_{2}-\mathrm{In}_{2} \mathrm{O}_{3}$ overlayers by ALD on porous SOFC state-of-the-art cathode. ECS Trans., 2007, 3, 261268.

[7] Beckel, D.; Bieberle-Hütter, A.; Harvey, A.; Infortuna, A.; Muecke, U.P.; Prestat, M.; Rupp, J.L.M.; Gauckler, L.J. Thin films for micro solid oxide fuel cells. J. Power Sources, 2007, 173, 325345 .

[8] Maier, J. Nano-ionics: Trivial and non-trivial size effects on ion conduction in solids. J. Phys. Chem., 2003, 217, 415-436.

[9] Maier, J. Transport in electroceramics: micro- and nano-structural aspects. J. Eur. Ceram. Soc., 2004, 24, 1251-1257.

[10] Kosacki, I.; Susuki, T.; Anderson, H.U.; Colomban, P. Raman scattering and lattice defects in nanocrystalline $\mathrm{CeO}_{2}$ thin films. Solid State Ionics, 2002, 149, 99-105.

[11] Jud, E.; Huwiler, C.B.; Gauckler, L.J. Sintering analysis of undoped and cobalt oxide doped ceria solid solutions. J. Am. Ceram. Soc., 2005, 88, 3013-3019.

[12] Liu, F.; Kirchheim, R. Nano-scale grain growth inhibited by reducing grain boundary energy through solute segregation. $J$. Cryst. Growth, 2004, 264, 385-391.

[13] Guinebretière, R.; Dauger, A.; Lecomte, A.; Vesteghem, H. Tetragonal zirconia powders from the zirconium n-propoxideacetylacetone-water-isopropanol system. J. Non Cryst. Sol., 1992, 542, 147-148.

[14] Chatry, M.; Henry, M.; Livage, J. Synthesis of non-aggregated nanometric crystalline zirconia particle. Mater. Res. Bull., 1994, 29, 517-522.

[15] Landau, L.; Levich, B. Dragging of a liquid by a moving plate. Acta Physicochim, URSS, 1942, 17, 42.

[16] Boukamp, B.A. A Nonlinear least squares fit procedure for analysis of immittance data of electrochemical systems. Solid State Ionics, 1986, 20, 31-44.

[17] Briois, P.; Lapostolle, F.; Demange, V.; Djurado, E.; Billard, A. Structural investigations of YSZ coatings prepared by DC magnetron sputtering. Surf. Coat. Technol., 2007, 201, 6012-6018.

[18] Perry, F.; Lelait, L.; Pigeat, P.; Billard, A.; Frantz, C. Le Vide: Science, Techniques et Applications, 1999, 291, 285.

[19] Lapostolle, F. Ph.D. Thesis, University of Nancy, 2001.

[20] Lapostolle, F.; Perry, F. and Billard, A. Application of optical transmission interferometry for in-situ structural investigations of titanium dioxide sputter-deposited coatings. Surf. Coat. Technol., 2006, 201, 2633-2638.

[21] Jacobsen, T.; Zachau-Christiansen, B.; Bay, L. and Skaarup, S.; Poulsen, F.W.; Bonanos, N.; Linderoth, S.; Mogensen, M. and Zachau-Christiansen, B. Eds. High temperature Electrochem. Ceramics and Metals, Risø National Laboratory, Denmark, 1996, p. 29.

[22] Schouler, E. J. L.; Mesbahi, N.; Vitter, G. In situ study of the sintering process of yttria stabilized zirconia by impedance spectroscopy. Solid State Ionics, 1983, 9, 989.

[23] Jiang, S.P.; Love, J.G.; Ramprakash, Y. Electrode behaviour at $(\mathrm{La}, \mathrm{Sr}) \mathrm{MnO}_{3} / \mathrm{Y}_{2} \mathrm{O}_{3}-\mathrm{ZrO}_{2}$ interface by electrochemical impedance spectroscopy. J. Power Sources, 2002, 110, 201-208.

[24] Tsuneyoshi, K.; Mori, K. Sawata, A.; Mizusaki, J. and Tagawa, H. Kinetic studies on the reaction at the $\mathrm{La}_{0.6} \mathrm{Ca}_{0.4} \mathrm{MnO}_{3} / \mathrm{YSZ}$ interface, as an SOFC air electrode. Solid State Ionics, 1989, 35, 263-268.

[25] Jiang, S.P.; Zhang, J.P.; Forger, K. Deposition of Chromium Species at Sr-Doped $\mathrm{LaMnO}_{3}$ electrodes in solid oxide fuel cells II. Effect on $\mathrm{O}_{2}$ reduction reaction. J. Electrochem. Soc., 2000, 147, 3195-3205.

[26] Youngblood, G. E.; Rupaal, A. S.; Pederson, L. R. and Bates, J. L. In Solid Oxide Fuel Cells III, Signal S.C and H. Iwahara, H., Ed. 
PV 93-4. The Electrochemical Society, Pennington, NJ, 1993, p. 585.

[27] Sasaki, K.; Wurth, J.-P.; Gschwend, R.; Godickemeier, M. and Gauckler, L. J. Microstructure-property relations of solid oxide fuel cell cathodes and current collectors. J. Electrochem. Soc., 1996, 143, 530-543.

[28] Murray, E. P.; Tsai, T.; Barnett, S. A. Oxygen transfer processes in (La,Sr)MnO3/Y2O3-stabilized $\mathrm{ZrO}_{2}$ cathodes: an impedance spectroscopy study. Solid State Ionics, 1998, 110, 235-243.

[29] Jiang, Y.; Wang, S.; Zhang, Y.; Yan, J.; Li, W. Electrochemical reduction of oxygen on a strontium doped lanthanum manganite electrode. Solid State Ionics, 1998, 110, 111-119.
[30] Kunznecov, M.; Otscchik, P.; Trofimenko, N.; Eichler, K. Oxygen transport in the SOFC cathode. Russ. J. Electrochem., 2004, 40, 1162-1169.

[31] Takeda, Y.; Kanno, R.; Noda, M.; Tomida, Y. and Yamamoto, O. Cathodic polarization phenomena of perovskite oxide electrodes with stabilized zirconia. J. Electrochem. Soc., 1987, 134, 26562661.

[32] Brant, M.C.; Matencio, T.; Dessemond, L.; Domingues, R.Z. Electrical degradation of porous and dense LSM/YSZ interface. Solid State Ionics, 2006, 177, 915-921.

[33] Barbucci, A.; Bozzo, R.; Cerisola, G.; Costamagna, P. Characterisation of composite SOFC cathodes using electrochemical impedance spectroscopy: Analysis of Pt/YSZ and LSM/YSZ electrodes. Electrochim. Acta, 2002, 47, 2183-2188.

(C) Benamira et al.; Licensee Bentham Open.

This is an open access article licensed under the terms of the Creative Commons Attribution Non-Commercial License (http://creativecommons.org/licenses/by$\mathrm{nc} / 3.0 /$ ) which permits unrestricted, non-commercial use, distribution and reproduction in any medium, provided the work is properly cited. 